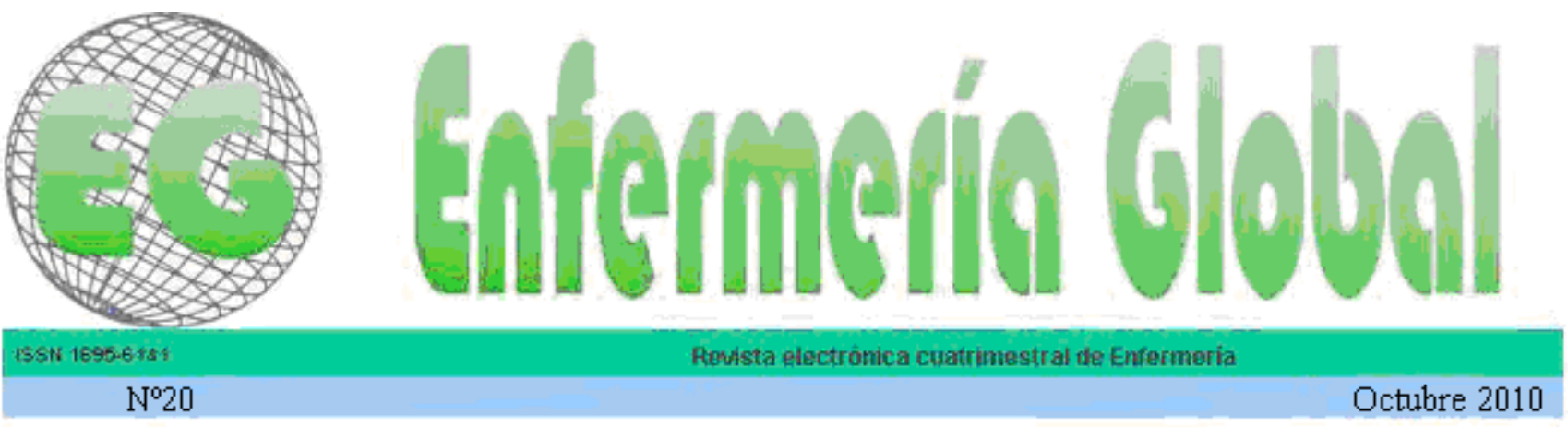

www.um.es/eglobal/

REVISIONES

\title{
DIRECTRICES PARA EL TRATAMIENTO DE ÚLCERA VENOSA
}

DIRETRIZES PARA O TRATAMENTO DA ÚLCERA VENOSA

\section{*Guimarães Barbosa, JA., ** Nogueira Campos, LM.}

\author{
*Mestre em Enfermagem. Especialista em Terapia Nutricional Enteral e Parenteral. Presidente do Comitê de \\ Enfermagem da Sociedade Brasileira de Nutrição Enteral e Parenteral. ** Enfermeira. Pós - graduanda em \\ Saúde Coletiva pela UFMG. Belo Horizonte, Brasil.
}

Palabras clave: Úlcera venosa; Insuficiencia venosa crónica; Tratamiento de heridas.

Palavras-chave: Úlcera venosa; Insuficiência venosa crônica; Tratamento de feridas.

Keywords: Venous ulcers, Chronic Venous Insufficiency, and Wound Treatment

\section{RESUMEN}

Se trata de la revisión de publicaciones sobre úlceras de etiología venosa. Considerando la alta incidencia y lo mucho que prevalecen las úlceras venosas, así como las interferencias que las mismas causan en la vida de los pacientes, y la variedad de conductas utilizadas para el tratamiento de las mismas, este estudio se propone actualizar las directrices sobre el tratamiento de las úlceras venosas. Los trabajos analizados demuestran que a pesar de los avances de las investigaciones, todavía persiste la duda sobre el mejor tratamiento: ¿Se debe o no combinar el tratamiento oclusivo con la terapia compresiva?. De todo ello se concluye que las principales directrices para el tratamiento de la úlcera venosa deben seguir cuatro pasos: tratamiento del estado venoso, con terapia y compresas; terapia tópica, escogiendo cubiertas locales que mantengan húmedo y limpio el fondo de la herida y sean capaces de absorber el ex-sudado; control de la infección con terapia antibiótica sistémica y prevención de recidivas.

\section{RESUMO}

Trata-se de uma revisão de publicações sobre úlceras de etiologia venosa. Considerando a alta incidência e prevalência de úlceras venosas bem como as interferências que as mesmas causam na vida dos pacientes e a diversidade de condutas utilizadas para o tratamento das úlceras, este estudo se propõe a uma atualização sobre as diretrizes no tratamento da úlcera venosa. Os trabalhos analisados demonstram que apesar dos avanços das pesquisas, ainda persiste a dúvida a respeito do melhor tratamento para úlcera venosa, gerando uma diversidade de tratamento: deve-se ou não combinar o curativo oclusivo com a terapia compressiva? Conclui-se que as principais diretrizes para o tratamento da úlcera venosa deve estar amparadas em quatro condutas: tratamento da estase venosa, utilizando o repouso e a terapia compressiva; terapia tópica, com escolha de coberturas 
locais que mantenham úmido e limpo o leito da ferida e sejam capazes de absorver o exsudato; controle da infecção com antibioticoterapia sistêmica e prevenção de recidivas.

\section{ABSTRACT}

This is a review of publications on venous ulcers. Considering the high incidence and prevalence of venous ulcers as well their interference in patients' lives and the different ways of treatment, this study proposes a modernization of guidelines on treating venous ulcers. The results showed that although the research has advanced, there still persists doubt as to which is the best venous ulcers treatment: Should the occlusive covering and compressive therapy be used together or not? The study concludes that the main guidelines to ulcers treatment should be based on four conducts: The static venous treatment, based on therapy and compress therapy; topical therapy, choosing the best local covering to keep the wounds humid and clean in order to absorb the exudation; infection control by using systemic antibiotic therapy and prevention of relapse.

\section{INTRODUCCIÓN}

De entre las úlceras encontradas en los miembros inferiores, la úlcera de etiología venosa es la que tiene mayor arraigo. Corresponde aproximadamente a entre el $80 \%$ y el $90 \%$ de las úlceras encontradas en esa localización, siendo la insuficiencia venosa crónica (IVC) la principal responsable por su aparición.

Entender su etiopatogenia y su fisiopatología así como toda la problemática consiguiente es importante no solo para efectuar el tratamiento adecuado sino, principalmente, para la aplicación de medidas preventivas que procuren disminuir la aparición de complicaciones y su reincidencia ${ }^{1}$. La evaluación clínica por medio de la historia, antecedentes y examen físico es fundamental para establecer el diagnóstico de la úlcera. ${ }^{2}$

De acuerdo con Orozco y Martins ${ }^{3}$, el enfermero ejerce un importante papel en el tratamiento de las lesiones por ser el profesional en condiciones de evaluar el cuidado diario, incorporando los principios técnico-científicos y los valores éticos indispensables para la práctica profesional.

El tratamiento de heridas es un proceso dinámico que depende de evaluaciones sistematizadas, prescripciones diferentes de frecuencia y tipo de cura o cobertura necesarias, que pueden ser variables de acuerdo con el momento evolutivo del proceso cicatrizante. El tratamiento de cualquier herida debe ser personalizado, es decir, debemos considerar todos los factores individuales del paciente y los recursos materiales y humanos de que disponemos, y que él mismo tenga condiciones de continuarlo después del alta. La elección debe evaluarse con relación a las indicaciones, a las contraindicaciones, a los costes y a la eficacia ${ }^{4}$.

Para Borges ${ }^{5}$, aún persiste la duda con respecto al mejor tratamiento para la úlcera venosa, generándose una diversidad de los mismos. En el caso de la úlcera venosa, el tratamiento debe ampararse en cuatro conductas: tratamiento de la estasis venosa con reposo y terapia compresiva; terapia tópica, con elección de coberturas locales que mantengan húmedo y limpio el lecho de la herida y sean capaces de absorber el exudado; control de la infección con antibioticoterapia sistémica y prevención de recidivas.

Considerando los impactos en la calidad de vida de los portadores de úlcera venosa, así como los costes elevados, el tiempo prolongado de tratamiento y las dudas y divergencias verificadas en la práctica profesional, este trabajo proporcionará a los profesionales de la 
enfermería y a los demás profesionales que tratan del asunto, una profundización del tema y la actualización sobre los protocolos de asistencia a los pacientes.

\section{METODOLOGİA}

Para la realización de este trabajo se han revisado artículos científicos, libros, manuales y tesis de doctorado publicados en el período de1995 a 2007. Las fuentes de investigación utilizadas fueron las bases de datos Scielo y Bireme, usando como referencia para la búsqueda las palabras clave: úlcera venosa, insuficiencia venosa crónica y tratamiento de heridas. Se identificaron, inicialmente, un total de 35 publicaciones, reduciéndose a 23 después de la evaluación de sus referencias.

De acuerdo con Vieira y Hossne ${ }^{6}$, se realiza una Revisión Bibliográfica que nos muestra la evolución del conocimiento sobre el tema y resume lo que es realmente importante sobre el mismo.

\section{CONCEPTO, INCIDENCIA, ETIOPATOGENIA Y FISIOPATOLOGÍA DE LA ÚLCERA VENOSA}

La úlcera de pierna es un síndrome caracterizado por la pérdida circunscrita o irregular de tegumento (dermis o epidermis), pudiendo afectar al tejido subcutáneo y subyacente, que se produce en las extremidades inferiores y cuya causa está, generalmente, relacionada al sistema vascular arterial o venoso ${ }^{7}$. Las úlceras venosas son lesiones crónicas asociadas a hipertensión venosa de los miembros inferiores y corresponden a un porcentaje que varía, aproximadamente, entre el 80 y el $90 \%$ de las úlceras que aparecen en esa localización y configuran, en todo el mundo, un problema grave, con considerable impacto socioeconómico como pérdida de días de trabajo, jubilación anticipada, gastos terapéuticos prolongados, además de restringir las actividades de la vida diaria $a^{1,8,9,10,11,12 .}$

Bergonse y Rivitti ${ }^{13}$, afirman que las úlceras de los miembros inferiores son muy frecuentes en todo el mundo y tienen gran impacto en la calidad de vida y productividad del individuo, además de un alto coste para la sanidad pública.

La insuficiencia venosa crónica (IVC) es la causa más común de las úlceras de pierna. Se define como una anormalidad del funcionamiento del sistema venoso causada por una incompetencia valvular, asociada o no a la obstrucción del flujo venoso. Puede afectar al sistema venoso superficial, al profundo o a ambos. Además, la disfunción venosa puede ser el resultado de un disturbio congénito o puede ser adquirida. ${ }^{12,14}$ De acuerdo con Aguiar ${ }^{2}$, la IVC es responsable por el $75 \%$ de las úlceras de pierna. Las demás son provocadas por enfermedad arterial obstructiva periférica, neuropatía periférica, enfermedades infectocontagiosas, reumatológicas, hematológicas y tumores.

Yamada ${ }^{11}$ cita que, de hecho, la bibliografía es unánime al considerar la úlcera de etiología venosa como la más común de las úlceras de la pierna. Los porcentajes varían del 42 al $90 \%$ y la historia está marcada por la reincidencia. Aproximadamente el $70 \%$ de las úlceras se abren de nuevo tras la cicatrización.

En Estados Unidos aparecen cerca de 600.000 casos nuevos, de úlcera de pierna, al año y, en su mayoría, venosa. En Suiza la padece el 1\% de los individuos en activo. En Europa y 
Australia la incidencia relatada varía del 0,3 al 1\%, mientras que la incidencia mundial está alrededor del $2,7 \%{ }^{7,9,10,11}$. De acuerdo con Maffei ${ }^{15}$, en Dinamarca, se halló una prevalencia del 3,9\% de úlceras venosas abiertas o cicatrizadas. En la antigua Checoslovaquia, el 1\%. En Suecia, entre el 4 y el $5 \%$ de la población por encima de 80 años presenta dicha patología 7 .

De acuerdo con Yamada ${ }^{11}$, los resultados de los dos estudios brasileños realizados indican que se superan los índices de la población en general. El primero obtuvo un índice del 3,6\% (el $2,3 \%$ en hombres y el $4 \%$ en mujeres) y el segundo del 3,2\% en hombres y del 3,9\% en mujeres. La autora, además, afirma que la úlcera venosa es más frecuente en ancianos, especialmente en los que tienen entre 65 y 70 años. La relación entre mujeres y hombres ancianos es de 3 a 1, siendo el factor de preponderancia en las mujeres la longevidad, pues por debajo de los 40 años la relación es la misma para ambos sexos.

Según França y Tavares, el sistema venoso es un sistema de capacitancia, funcionando como depósito sanguíneo que, normalmente, tiene la función de transportar la sangre sin oxígeno de vuelta al corazón. Las venas de la pantorrilla, asociadas a los tejidos circundantes, forman una unidad funcional conocida como bomba muscular o corazón periférico, activo actuante en el drenaje de la sangre venosa durante el ejercicio. En condiciones normales, el flujo de sangre se hace únicamente en una dirección, a través de tres sistemas de venas, distintos anatómica y funcionalmente, que son: el superficial, el profundo y el comunicante o perforante, a través del cual se produce la comunicación entre los otros dos. Las venas de estos tres sistemas poseen innumerables válvulas que orientan el flujo sanguíneo en un único sentido, de las venas del sistema superficial hacia el sistema profundo, e impiden el reflujo del mismo durante la relajación de la musculatura de las piernas. ${ }^{11,16}$

El flujo venoso también es auxiliado por la musculatura de la pantorrilla, que funciona como una verdadera bomba periférica, ayudando a las válvulas a superar la fuerza de la gravedad, impulsar la sangre hacia el corazón y disminuir la presión en el interior de las venas. La presión venosa es el resultado de la presión hidrostática ejercida por la columna sanguínea entre las piernas y la aurícula derecha. En posición supina, la presión en las venas profundas alcanza casi la de $0 \mathrm{~mm}$ de $\mathrm{Hg}$, pero de pie aumenta drásticamente, llegando generalmente a los 80 ó $90 \mathrm{~mm}$ de $\mathrm{Hg}$ y al caminar cae a $30 \mathrm{~mm}$ de $\mathrm{Hg}$. Al caminar, aquel grupo muscular se contrae y ejerce presión sobre las venas profundas, provocando una caída de la presión venosa hasta su estado fisiológico.

En resumen, la función fisiológica depende de la integridad anatómica de las venas, de la competencia del sistema valvular y del buen funcionamiento de la bomba periférica. ${ }^{1,11,17}$ Es el fallo de este mecanismo el que desencadena la hipertensión venosa al moverse, llevando a una acumulación excesiva de líquido y de fibrógeno en el tejido subcutáneo, originándose el edema, la lipodermatoesclerosis y, finalmente, la ulceración. Según França y Tavares, aún permanece sin explicación por qué esa presión elevada lleva a la formación de úlceras en los miembros inferiores.

La fisiopatología de la úlcera venosa no está bien establecida. ${ }^{11,15}$ Se han propuesto algunas teorías para explicar la patogénesis de la úlcera. Grahan y colaboradores, citado por Maffei $^{15}$, sugiere que la hipertensión venosa de larga duración sería, eventualmente, la causa de esas alteraciones vasculares. Dodd y Cockett, también citados por Maffei ${ }^{15}$, opinan que el factor fundamental para la hipertensión venosa es la insuficiencia de las venas perforantes de la región del tobillo. Browse y Burnand, citados por Yamada y Santos 1, piensan que a lo largo del tiempo, las presiones elevadas en el interior de los vasos 
provocan alteraciones en la microcirculación. Las paredes de los vasos se dañan, trayendo consigo un aumento de la permeabilidad capilar con liberación de macromoléculas de su interior hacia la piel, lo que provoca las alteraciones cutáneas observadas bajo la forma de edemas, eczemas, hiperpigmentación, lipodermatoesclerosis, culminando con la ulceración del tejido.

Otra teoría, denominada "white cell trapping" o "teoría de los leucocitos" fue descrita por Coleridge Smith y colaboradores en 1988. Los autores proponen que la hipertensión venosa reduce el flujo sanguíneo en el capilar, permitiendo que los glóbulos blancos se agrupen en la pared del endotelio y ocluyan los capilares causando isquemia local y bloqueando el transporte del oxígeno por los eritrocitos. Los neutrófilos adheridos se activan y liberan radicales libres, citoquinas y substancias quimiotáxicas que causan daños a la vasculatura de la dermis, y la respuesta inflamatoria resultante lleva a la muerte del tejido y a la formación de la úlcera. ${ }^{1}$ Una hipótesis alternativa propuesta por Falange y Eaglstein, publicada en 1993, fue la llamada "trap growth factor hipótesis". Según la visión de estos autores, el fibrinógeno y otras macromoléculas, como la albúmina y la Alfa-2 macroglobulina liberadas por la dermis como consecuencia de la hipertensión venosa, se agrupan con factores de crecimiento y otras substancias estimulantes u homeostáticas, volviéndose incompatibles para el mantenimiento de la integridad del tejido y para el proceso de reparación. ${ }^{1}$

Aunque el mecanismo exacto aún sea desconocido, hay un consenso entre los autores sobre que la hipertensión venosa sea el factor más frecuente para la ulceración de las extremidades inferiores. ${ }^{11}$

Se constata que, aun siendo oscuro el exacto mecanismo de la patogénesis de la úlcera venosa, los autores consideran que todas las hipótesis teóricas descritas no son excluyentes $\mathrm{y}$, posiblemente, todas puedan estar relacionadas con el proceso de ulceración venosa. ${ }^{11}$

\section{CARACTERİSTICAS DE LA ÚLCERA VENOSA Y DIAGNÓSTICO DIFERENCIAL}

Las úlceras venosas, al surgir espontáneamente, tienden a localizarse en la región del maléolo interno. Sin embargo, pueden estar presentes en otras partes de las piernas cuando son originadas por traumas o infecciones. ${ }^{1,11,15,16,18,19}$ De un modo general las úlceras venosas son más superficiales que las úlceras de pierna de otras etiologías; los contornos son normalmente irregulares; son extremadamente exudativas; el dolor es, generalmente, variado, mejorando con la elevación del miembro; hay presencia de edema y la evolución es lenta. ${ }^{11}$

La evaluación física de la úlcera venosa debe dirigirse al estado vascular, con atención a las señales clínicas específicas de la IVC tales como edema, eczema, hiperpigmentación, hinchazón del tobillo, venas varicosas, lipodermatoesclerosis, dolor y otros. ${ }^{11}$

De acuerdo con Borges ${ }^{5}$, las heridas de etiología venosa están, generalmente, recubiertas por tejido necrótico membranoso, superficial, amarillento e imbricado en el tejido de granulación, y son muy exudativas.

El diagnóstico clínico puede facilitarse por medio de la comparación de las diferencias entre las úlceras venosas y las arteriales: la úlcera venosa tiende a localizarse en el tercio inferior de la pierna, siendo común en el maléolo medio, mientras que la úlcera arterial puede aparecer en los dedos, en el pié, en el talón; el desarrollo de la úlcera venosa es lento mientras que el de la arterial es rápido; la úlcera venosa presenta contornos superficiales e 
irregulares y el tejido profundo no está afectado; sin embargo la úlcera arterial es generalmente profunda, afectando tendones y músculos, y los contornos están bien definidos; la úlcera venosa presenta manchas varicosas de color castaño, eczema y está caliente al toque, mientras que la arterial presenta piel brillante, cianosis y está fría al toque; el edema está presente en la úlcera venosa y prácticamente ausente en la úlcera arterial; el dolor es variable en la úlcera venosa, mejorando con la elevación del miembro, e intenso en la úlcera arterial; en la úlcera venosa el pulso está presente mientras que en la arterial ha disminuido o está ausente. ${ }^{11,16}$

De acuerdo con Dealey ${ }^{16}$, se debe hacer una evaluación completa de la pierna afectada, pues es importante para descartar la posibilidad de enfermedad arterial; los tratamientos para úlceras venosas y arteriales no son compatibles.

Según el citado Dealey ${ }^{16}$, se puede hacer el diagnóstico diferencial entre úlceras venosas y arteriales, evaluando el suministro de sangre a las piernas. La mejor manera de hacerlo es por medio de ultrasonografía Doppler que se usa para comparar la presión sanguínea en la parte inferior de la pierna con la presión braquial. En general, la presión se presenta bajo la forma de un índice: el índice de presión tobillo/brazo (IPTB), calculado por medio de la división entre la presión sistólica en el tobillo y la presión sistólica braquial. De acuerdo con la autora, un IPTB de 0,9 o más indica suministro arterial normal para la pierna. Cuando está por debajo de 0,9 indica la presencia de alguna isquemia. La terapia de compresión no se debe usar si el IPTB estuviese por debajo de 0,8.

Para Bergonse y Rivitti ${ }^{13}$, el índice tobillo/brazo es un método no invasivo, usado en la práctica médica para la detección de insuficiencia arterial. Este examen se basa en la medida de las presiones arteriales del tobillo y los brazos, usando un esfignomanómetro y un aparato de ultrasonido Doppler, portátil. Los autores consideran que los pacientes con valor de IPTB igual o mayor a 1 están normales y en general asintomáticos; aquellos con IPTB entre 0,7 y 0,9 son portadores de un grado leve de insuficiencia arterial y pueden presentar cuadro clínico de claudicación intermitente; pacientes con IPTB entre 0,5 y 0,15 muestran un grado, de moderado a grave, de insuficiencia arterial y pueden presentar, clínicamente, dolor en reposo; pacientes con IPTB por debajo de 0,15 presentan un grado grave de insuficiencia arterial, con presencia de necrosis y riesgo de amputación del miembro afectado. Se considera el IPTB $<0,8$ como valor indicador para rechazar la terapia de alta compresión, bajo riesgo de necrosis del miembro.

En el año 2006 los mismos autores realizaron un estudio, con el objetivo de detectar alteraciones arteriales en pacientes con úlceras venosas crónicas de los miembros inferiores, empleando método no invasivo, con la idea de distinguir a aquellos en que estaría contraindicado el tratamiento compresivo. Se estudiaron 40 enfermos portadores de úlcera venosa crónica, con la intención de evaluar la presencia de enfermedad arterial periférica, por la medida del índice tobillo/brazo por ultrasonido Doppler. Dicho índice apareció alterado (menos que 1) en 9/22 (el 40,9\%) de enfermos con úlcera venosa crónica e hipertensión arterial concomitante, y apenas en 1/13 (el 7,7\%) de enfermos de úlcera venosa crónica sin hipertensión arterial. Se concluyó que enfermos de úlcera venosa crónica e hipertensión arterial concomitante deben someterse rutinariamente a la medida del índice tobillo/brazo para la detección de una posible insuficiencia arterial periférica asociada.

\section{EL TRATAMIENTO DE LA ÚLCERA VENOSA}

El tratamiento de heridas es un proceso dinámico que depende de evaluaciones sistematizadas, prescripciones diferentes de frecuencia y tipo de cura o cobertura 
necesarias, que pueden ser variables de acuerdo con el momento evolutivo del proceso cicatricial. El tratamiento de cualquier herida debe ser personalizado, es decir, debemos considerar todos los factores individuales y los recursos materiales y humanos de que disponemos, así como las condiciones socioeconómicas del paciente para la continuidad del tratamiento domiciliario. El resultado de la elección debe evaluarse en relación a las indicaciones, a las contraindicaciones, a los costes y a la eficacia. ${ }^{4}$

La eficacia del tratamiento de heridas depende de la eliminación o control de los factores causales, de un adecuado soporte sistémico y de la prescripción de la terapia tópica apropiada, para lo cual es fundamental evaluar al paciente, considerándose su estado general, su estado nutricional, la edad, las enfermedades asociadas, el uso de medicamentos, los posibles disturbios metabólicos, hidroelectrolítico, entre otros. ${ }^{20}$ Orosco, Martins $^{3}$, añaden que el éxito en el tratamiento de heridas debe basarse en varios factores, como la identificación del agente etiológico, de la patología de base y de la fase evolutiva de la herida.

En el caso de la úlcera venosa el tratamiento debe ampararse en cuatro conductas: tratamiento de la estasis venosa con reposo y terapia compresiva; terapia tópica, con elección de cobertura local que mantenga húmedo y limpio el lecho de la herida y sea capaz de absorber el exudado; control de la infección con antibioticoterapia sistémica, conforme con los resultados del Gram, del cultivo y del antibiograma, y en la prevención de recidivas. ${ }^{5}$

Se observa que a pesar de los avances en las investigaciones aún persiste la duda respecto al mejor tratamiento para la úlcera venosa: ¿se debe o no combinar el vendaje oclusivo con la terapia compresiva, generando una diversidad de tratamientos? Muchos profesionales afirman que basta la terapia compresiva para provocar la cicatrización de las úlceras venosas. $^{5}$

De acuerdo con Borges ${ }^{5}$, para lograr la cura de la úlcera venosa es importante el tratamiento tópico que combina la terapia compresiva con la tópica. La primera requiere el uso de compresión externa para facilitar el retorno venoso, reduciendo así la hipertensión venosa crónica, y la segunda requiere el uso de coberturas capaces de absorber el exudado y crear un ambiente propicio para el desarrollo del proceso de cicatrización.

\section{LA LIMPIEZA DE LA ÚLCERA}

El tratamiento de heridas crónicas se inicia, en general, con la limpieza adecuada que comprende la aplicación de un fluido, no tóxico para la herida, capaz de remover del lecho de la lesión el tejido necrótico licuado, el exudado, los cuerpos extraños, incluyendo los restos del vendaje anterior, para crear un ambiente óptimo para la cicatrización, sin provocar daños al tejido sano. ${ }^{5}$

La técnica de limpieza empleada debe respetar la viabilidad del tejido de granulación, preservar el potencial de recuperación de la herida y hacer lo posible por no causar traumatismos. 18

En la literatura aparece una duda con respecto a la solución más adecuada para la limpieza de la herida. Varios estudios señalan que la mayoría de las soluciones antisépticas tienen su acción mermada o inhibida en presencia de materia orgánica, además de retardar el proceso de cicatrización al inhibir la producción de fibroblastos, células esenciales para la formación del tejido de granulación. ${ }^{5}$ 
Para Borges ${ }^{5}$, se han recomendado muchas soluciones para la limpieza de la superficie de las heridas. La solución salina (al 0,9\%) es la más indicada por ser una solución isotónica, tener el mismo pH del plasma y no interferir en el proceso de cicatrización normal; además de no causar daños en los tejidos, no provoca reacciones de hipersensibilidad o alérgicas y tampoco altera la microbiótica de la piel, permitiendo el crecimiento de organismos poco virulentos. Otra opción de solución es el agua del grifo, que se usa comúnmente para la limpieza de heridas porque es de fácil acceso, eficiente y de bajo coste; el problema en relación a su uso es que, muchas veces, el profesional no tiene certeza sobre su calidad.

Borges cita que, según Fernández, Griffiths (2002), todavía persisten muchas dudas al respecto del procedimiento de limpieza de la herida, incluso, sobre las ventajas del exudado del lecho de la herida dado que contiene factores de crecimiento y bioquímicos que contribuyen en la cicatrización de la herida. Pero la limpieza de la herida continuará formando parte integral del proceso de tratamiento hasta que otra investigación nos proporcione evidencias acerca de las desventajas de su uso.

De acuerdo con Yamada ${ }^{11}$, la fuerza hidráulica empleada en la irrigación debe estar por debajo de 15 psi (libra/pulgada), considerando que 8 psi es la presión adecuada para la remoción, que puede realizarse con una jeringa de $35 \mathrm{ml}$ y aguja de calibre 19 , según patrón norteamericano. Una presión superior a 15 psi puede provocar traumas en el tejido sano, y con una presión inferior a 8 psi se corre el riesgo de no lograr una limpieza efectiva. Como en el mercado brasileño no se encuentran jeringas de $35 \mathrm{ml}$. se hace la irrigación del lecho de la herida de formas diferentes, utilizando aguja de calibre 12 en jeringa de $20 \mathrm{ml}$. o frasco, de solución salina isotónica (al 0,9\%) de 125 o $250 \mathrm{ml}$. perforado con agujas de diferentes calibres. Se desconoce la presión alcanzada por tales mecanismos y no se dispone de publicaciones que hagan referencia al hecho.

Para Oliveira, Martinho, Nunes ${ }^{20}$, la limpieza de la herida debe realizarse con solución fisiológica a presión, usando un frasco de suero fisiológico de $250 \mathrm{ml}$. perforado con una aguja 25/8, con el fin de provocar presión suficiente para remover el exudado de la herida y eventuales cuerpos extraños.

La irrigación debe ser exhaustiva hasta la retirada de los detritos y del exudado presente en el lecho de la herida. El volumen de la solución salina isotónica (al 0,9\%) necesario va a depender de la extensión, profundidad y cantidad de secreción presente. La presión del chorro de la solución salina debe ser la suficiente para lograr los objetivos sin provocar daños. Se debe tener en cuenta que todo el proceso considere el control de la concentración bacteriana. ${ }^{18}$

La división celular en el organismo humano ocurre a la temperatura fisiológica de $37^{\circ} \mathrm{C}$, por lo que la herida, después de limpia, necesita 30 ó 40 minutos para recuperar esa temperatura y 3 ó 4 horas para alcanzar la velocidad normal de división celular. Por lo tanto, para preservar dicho proceso celular es importante mantener la temperatura en torno a $37^{\circ}$ $\mathrm{C}$, lo que exige el uso de la solución salina isotónica, calentada. ${ }^{18}$ Según Blanes ${ }^{21}$, las soluciones utilizadas deben, preferentemente, calentarse para evitar la reducción de la temperatura en el lecho de la herida. Una temperatura constante de $37^{\circ} \mathrm{C}$ estimula la mitosis durante la granulación y epitelización.

\section{DESBRIDAMIENTO DE LA ÚLCERA}

Las heridas con presencia de tejido necrótico, además de la limpieza mecánica requieren el desbridamiento, es decir la eliminación del material extraño o tejido no viable, hasta la 
exposición del tejido sano. En la úlcera de etiología venosa, generalmente, ese tejido está más superficial, adherido, tiene color amarillo y está imbricado con el tejido de granulación. ${ }^{5}$

Según Borges ${ }^{19}$, el tejido necrótico está formado, fundamentalmente, por colágeno desnaturalizado (el $79 \%$ de su peso). La adhesión de ese tejido al fondo de la herida se realiza a través de los puentes de colágeno en su forma natural: fibras colágenas. La presencia de tejido necrótico impide muchas veces la epitelización marginal.

El profesional, al examinar la lesión crónica, debe estar atento a la presencia y a las características del tejido necrótico. Su presencia aumenta el riesgo de infección y retarda el proceso de cicatrización, dado que las heridas sólo se epitelizan en su ausencia. ${ }^{19}$

Según Borges ${ }^{5}$, el desbridamiento se obtiene por métodos mecánicos, autolíticos, químicos o enzimáticos. Pero en detrimento de las características del tejido necrótico de la úlcera venosa, es difícil y arriesgado el desbridamiento con instrumental cortante, pues no existe tejido necrótico suficiente para ser cortado con seguridad sin provocar traumatismo en el tejido de granulación. Hay que resaltar que el desbridamiento es particularmente importante cuando aparece infección.

De acuerdo con Borges ${ }^{18}$, en el método autolítico se produce la autolisis, o sea, la autodestrucción natural del tejido necrótico. Las enzimas presentes en los lisosomas se liberan después de la muerte celular, pasando a digerir el contenido de las células y necrosando el tejido. Este proceso atrae inicialmente a los neutrófilos polimorfonucleares y posteriormente a los macrófagos, hacia el área herida y necrosada, liberando más enzimas lisosomales que ayudan a digerir los detritos. Este método es selectivo y sólo se destruye el tejido no viable permaneciendo intacto el viable. Para este proceso de desbridamiento es necesario que el lecho de la herida se mantenga con una humedad fisiológica y temperatura en torno a $37^{\circ} \mathrm{C}$ porque la autolisis es un proceso activo que requiere enzimas y células. El desbridamiento autolítico presenta la ventaja de que es un método indoloro, no invasivo y selectivo, como hemos dicho, es decir, no presenta riesgo de dañar el tejido de granulación. Pero es un método lento si se lo compara con el químico o el mecánico.

En el método químico se utilizan enzimas proteolíticas con el propósito de obtener una rápida eliminación del tejido inviable por la degradación del colágeno, utilizándose más la colagenasa y la papaína. Estas enzimas descomponen las fibras del colágeno natural, que constituyen el fondo de la lesión, por medio de las cuales los detritos permanecen adheridos a los tejidos. Sin embargo, en este método enzimático no existe selectividad y se corre el riesgo de causar la degradación del tejido de granulación, ya que éste es rico en colágeno natural. $^{18}$

El método mecánico consiste en la eliminación de la necrosis del lecho de la herida usando la fuerza física, que se realiza por medio de la fricción, del paso de uso de la gasa húmeda a la seca y del instrumental cortante. Los dos primeros no son selectivos y el último dependerá de la forma de abordarlo el profesional y de su habilidad. Es un procedimiento invasivo, doloroso y con riesgos para el paciente. ${ }^{18}$

El desbridamiento lo puede realizar el médico y/o el enfermero siempre que tengan habilitación. De acuerdo con la Disposición COREM-MG 65/00, el enfermero especialista tiene autorización para realizar el desbridamiento mecánico, siempre que, al optar por él, tenga el dominio de la técnica, la habilidad en el manejo del instrumental y el conocimiento de las estructuras anatómicas. ${ }^{18}$ 


\section{LA NECESIDAD DE AMBIENTE HÚMEDO PARA LA CICATRIZACIÓN DE LA ÚLCERA}

La reparación del tejido exige que el ambiente local propicie la formación de colágeno, angiogénesis, epitelización y contractura de la herida, procesos que tienen más éxito en un ambiente local en que existan óptimas condiciones de temperatura, hidratación y oxigenación. ${ }^{3}$ La comprobación de la necesidad de un medio húmedo para promover la emigración celular y la formación del tejido de granulación ha traído nuevas concepciones para el tratamiento y cuidado de las lesiones. ${ }^{20}$

Diversos estudios demuestran que el mantenimiento del medio húmedo entre el lecho de la herida y la cobertura primaria, favorece y aumente la velocidad de cicatrización. Winter, en 1962, demostró que en medio húmedo, las enzimas como las colagenasas y las proteasas capacitan a las células para que emigren, a través de la herida, hacia las áreas húmedas donde hay fibrina. Como epitelización significa emigración celular, el medio húmedo favorece las condiciones fisiológicas para la cicatrización. ${ }^{4}$ También en 1962, Winter y Roove demostraron que la epitelización era el $50 \%$ más rápida en un ambiente húmedo y que la formación de costras era mínima. ${ }^{18,22}$

Según Meneghin, Vattimo ${ }^{23}$, las heridas mantenidas en ambiente húmedo cicatrizan de tres a cinco veces más rápido y con menor dolor que las lesiones sometidas a un ambiente seco. Mantener seco el lecho de la herida provoca dolor debido a la exposición de las terminaciones nerviosas, apareciendo resecamiento y muerte celular. ${ }^{23}$

De acuerdo con França,Tavares, el ambiente húmedo evita la formación de costras y aumenta la velocidad de emigración de las células epiteliales, de la síntesis de colágeno, de la formación del tejido de granulación y la de la angiogénesis. Blanes ${ }^{21}$ añade, completando lo anterior, que los efectos beneficiosos del medio húmedo incluyen: prevención de deshidratación y muerte célular, angiogénesis acelerada, desbridamiento autolítico y reducción del dolor.

\section{TERAPIA TÓPICA}

Las heridas de etiología venosa están, generalmente, recubiertas por tejido necrótico membranoso, superficial, amarillento e imbricado en el tejido de granulación y son muy exudativas. Para el tratamiento tópico, además de la terapia compresiva es importante el uso de coberturas no adherentes, capaces de provocar el desbridamiento autolítico, de absorber el exudado y crear un ambiente propicio para el desarrollo del proceso de cicatrización, es decir, garantizar un ambiente oclusivo con baja concentración de microorganismos y con humedad y temperatura fisiológica, reduciendo, así, el tiempo de cicatrización. ${ }^{5}$

Para Borges ${ }^{5}$, la cobertura para la úlcera venosa debe ser capaz de absorber el exceso de exudado de la superficie de la herida, reducir el dolor de la úlcera, ser fácil de cambiar, no causar reacción alérgica, actuar como una membrana semipermeable, no causar traumatismos en la remoción, ser impermeable a microorganismos, además de proporcionar un ambiente térmico.

\section{TERAPIA COMPRESIVA Y REPOSO}

Desde que Unna, dermatologista del siglo XIX, desarrolló una venda compresiva de óxido de zinc para el tratamiento de úlceras venosas, la principal terapia para dichas heridas ha sido la compresión del miembro afectado. .,10 $^{2}$ 
La forma más adecuada de control clínico de la hipertensión venosa de los miembros inferiores es a través de la compresión del miembro. ${ }^{11}$ La terapia compresiva se puede conseguir con el uso de vendajes o medias, pudiendo estas clasificarse en elásticas (medias elásticas) o no elásticas (bota de Unna) y tener una o más capas. ${ }^{5}$

Según Borges ${ }^{5}$, para los pacientes con enfermedad venosa, la aplicación de compresión externa graduada puede disminuir o revertir los cambios que la hipertensión venosa crónica provoca en la piel y en la red vascular como hiperpigmentación, ezcema, lipodermatosclerosis, úlceras, varices. Su mecanismo de acción se da a través de la presión ejercida sobre la pierna, que obliga al fluido de los espacios intersticiales a retornar al compartimiento vascular o linfático. Como la presión en el interior de las venas es en gran parte hidrostática, cuando la persona está de pie, para revertir ese efecto se requiere que el nivel necesario de la presión externa se reduzca progresivamente en la pierna, desde la parte inferior hacia la superior, aplicando la mayor presión en la región del tobillo.

De acuerdo con Dealey ${ }^{16}$, el reposo con la elevación de las piernas también es útil, pues permite que la gravedad ayude al retorno venoso. Silva (1995), citado por Yamada ${ }^{11}$, recomienda que se haga reposo relativo, con las piernas elevadas, alternando con paseos, con los miembros sometidos a contención elástica.

\section{MEDIDAS PREVENTIVAS Y EVALUACIÓN DE LA ÚLCERA VENOSA}

De acuerdo con el Protocolo de Conducta para Úlceras Neutróficas y Traumáticas, del Ministerio de Sanidad ${ }^{24}$, la prevención de la úlcera venosa consiste en:

. Mantener reposo y elevación de los miembros inferiores. El paciente debe evitar estar de pie durante mucho tiempo y procurar reposar la pierna, elevándola a $30 \mathrm{~cm}$. por encima de la cadera, para ayudar al retorno venoso.

. Se aconseja el uso de medias de compresión, con presión entre 30 a $50 \mathrm{~mm}$ de Hg, para prevenir el edema y mejorar el efecto de la bomba muscular.

. El paseo y ejercicios de elevación del talón provocan flexión y contracción de los músculos de la pantorrilla, necesarios para el mantenimiento de la bomba muscular.

. Reducir el peso corporal.

- Realizar evaluación clínica periódica para búsqueda de presencia de anemia, desnutrición, hipertensión e insuficiencia cardiaca.

- Tratamiento de ezcemas de estasis con corticoterapia tópica.

. Evitar traumatismos en los miembros inferiores.

Tratamiento de infecciones bacterianas y fúngicas.

La evaluación clínica por medio de la historia, antecedentes y examen físico son fundamentales para establecer el diagnóstico de la úlcera. ${ }^{2}$

Para el acercamiento al paciente portador de úlcera de pierna, es importante que el profesional proceda a una evaluación vascular apropiada, que requiere observación del estado anatómico y funcional del sistema venoso superficial, profundo y perforante, y del sistema arterial; además de la verificación de señales de enfermedades sistémicas. Este es el primer paso para alcanzar el éxito final, es decir, la cicatrización completa de la herida. ${ }^{5}$

De acuerdo con Borges ${ }^{5}$, el cuidado de estos pacientes debe centrarse en las medidas para mejorar el retorno venoso, controlar los factores sistémicos y locales que interfieren en el proceso de cicatrización y conseguir un ambiente adecuado en la herida para impulsar la cicatrización. 


\section{CONSIDERACIONES FINALES}

El tratamiento de las úlceras venosas es un desafío al que se tienen que enfrentar los profesionales de la sanidad que se dedican a esta área. Los trabajos analizados en este trabajo señalan divergencias y dudas en lo que se refiere al tratamiento, aunque se sugieren algunas conductas para superarlo. Los resultados suscitan la necesidad de realización de cursos de especialización en el tratamiento de heridas como manera de alcanzar más conocimiento y habilidad para prestar asistencia a los portadores de úlceras venosas.

\section{REFERENCIAS}

1. Yamada BFA, Santos VLCG. Insuficiência Venosa Crônica. 2005. Disponível em: www.enfmedic.com.br

2. Aguiar ET, Pinto LJ, Figueiredo MA, Savino NS. Úlcera de Insuficiência Venosa Crônica. Diretrizes sobre Diagnóstico, Prevenção e Tratamento da Sociedade Brasileira de Angiologia e Cirurgia Vascular (SBACV). J Vasc Br 2005;4(Supl.2):S195-200.

3. Orosco SS, Martins EAP. Avaliação de feridas: uma descrição para sistematização da assistência. Enfermagem Brasil. Janeiro/Fevereiro 2006;5(1).

4. Bajay HM, Jorge SA, Dantas SRPE. Curativos e Coberturas para o Tratamento de Feridas. In: Jorge AS, Dantas SRPE. Abordagem Multiprofissional do tratamento de Feridas. São Paulo:Atheneu; 2003. p 247-59.

5. Borges EL. Tratamento tópico de úlceras venosas: proposta de uma diretriz baseada em evidências. Escola de Enfermagem de Ribeirão Preto da Universidade de São Paulo. Tese de doutorado.Ribeirão Preto, 2005. 305p.

6. Vieira S, Hossne WS. Metodologia Científica para a Área de Saúde. Rio de Janeiro: Editora Campos, 2002

7. Frade MAC, Cursi IB, Andrade FF e cols. Úlcera de perna: um estudo de caso em Juiz de Fora-MG (Brasil) e região. Anais Brasileiros de Dermatologia.v.80.n.1 Rio de Janeiro jan/fev 2005. Disponível em : www.scielo.com.br

8. Guimarães PCM, Leão PP, Neto BM, Aguiar ET, Miyake H, Miyake RK. Correlação clínico bacteriológica na úlcera de estase venosa. Revista de Angiologia e Cirurgia Vascular. Volume 4 - 1995, n 4.

9. Desidério VL, Lopes RGA, Dadalti P. Estudo evolutivo de úlceras venosas e mal perfurante planter após tratamento tópico com a associação de sulfadiazina de prata e nitrato de cério. Revista de angiologia e cirurgia vascular. Volume 10-2001. Número 4

10. Abdalla S, Dadalti P. Uso da sulfadiazina de prata associada ao nitrato de cério em úlceras venosas: relato de dois casos. An. Bras. Dermatol.v.78 n.2 Rio de Janeiro mar/abr 2003. Disponível em : www.scielo.com.br

11. Yamada BFA. Úlceras Venosas. In: Jorge AS, Dantas SRPE. Abordagem Multiprofissional do tratamento de Feridas. São Paulo:Atheneu; 2003. p 247-59.

12. França LHG, Tavares V. Insuficiência Venosa Crônica. Uma atualização. J Vasc Br 2003; 2(4): 318-28

13. Bergonse FN, Rivitti EA. Avaliação da circulação arterial pela medida do índice tornozelo/braço em doentes de úlcera venosa crônica. Na. Bras. Dermatol. v.81 n.2 Rio de Janeiro mar/abr 2006. Disponível em : www.scielo.com.br

14. Figueiredo MAM, Filho AD, Cabral ALS. Avaliação do efeito da meia elástica na hemodinâmica venosa dos membros inferioresde pacientes com insuficiência venosa crônica. J Vasc Br 2004;3(3):231-7

15. Maffei FHA. Insuficiência Venosa Crônica: conceito, prevalência, etiopatogenia e fisiopatologia. In: Doenças Vasculares Periféricas. $2^{\mathrm{a}}$ ed. Rio de Janeiro: Medsi; 1995. Cap 67,1003-1011. 
16. Dealey C. Ulceras Venosas. In: Cuidando de feridas: um guia para enfermeiras. $2^{\mathrm{a}}$ ed. São Paulo: Editora Atheneu; 2001. p.120-26.

17. Figueiredo M. Úlcera Venosa. Revista Virtual de Medicina. Volume 1 - Número 9 - Ano III (Jan/Fev/Mar de 2000). Disponível em: www.medonline.com.br

18. Borges EL. Limpeza e Desbridamento. In: Borges EL. Feridas; como tratar. Belo Horizonte: COOPMED, 2001. 130p

19. Borges EL. Fatores Interferentes no Processo de Cicatrização. In: Borges EL. Feridas; como tratar. Belo Horizonte: COOPMED, 2001. 130p

20. Oliveira AC, Martinho GH, Nunes AA. Feridas e Curativos. In: Martins AP. Manual de Infecção Hospitalar. Epidemiologia, Prevenção, Controle. $2^{a}$ ed. CClH-Hospital das Clínicas-UFMG. Belo Horizonte: MDSI; 2001. p. 325-35

21. Blanes, Leila. Tratamento de feridas. Baptista-Silva JCC, editor. Cirurgia vascular: guiailustrado. São Paulo: 2004. Disponível em: http://www.bapbaptista.com

22. Mandelbaum SH, Di Santis EP, Mandelbaum MHSA. Cicatrização: conceitos atuais e recursos auxiliares - Parte I. An. Bras. Dermatol. [periódico na Internet]. 2003 Ago [citado 2006 Out 26]; 78(4): 393-408. Disponível em: http://www.scielo.br/

23. Meneghin P, VattimoMFF. Fisiopatologia do Processo Cicatricial. In: Jorge AS, Dantas SRPE. Abordagem Multiprofissional do tratamento de Feridas. São Paulo:Atheneu; 2003. p 31-42.

24. Brasil. Ministério da Saúde. Secretaria de Políticas de Saúde. Departamento de Atenção Básica. Manual de condutas para úlceras neurotróficas e traumáticas / Ministério da Saúde, Secretaria de Políticas de Saúde, Departamento de Atenção Básica. - Brasília: Ministério da Saúde, 2002. 